\title{
A CONSEQUENCE OF REINFORCEMENTS IN ALUMINUM-BASED METAL MATRIX COMPOSITES: A LITERATURE REVIEW
}

\author{
Nishith Rathod ${ }^{1 *}$, Jyoti Menghani ${ }^{2}$ \\ ${ }^{1}$ Department of Mechanical Engineering, C. K. Pithawala College of \\ Engineering \& Tech., Surat, India. \\ ${ }^{2}$ Department of Mechanical Engineering, National Institute of Technology, \\ Surat, India.
}

Received 08.05.2019

Accepted 14.10.2019

\begin{abstract}
In the recent era, Metal Matrix Composites (MMCs) are one of the most vigorously studied topics in material science. Lightweight metals and its alloys create an intense attraction for tailoring new metal matrix composites to overcome conventional limitations like low strength. Aluminum metal matrix composites signify to the high-grade lightweight high-performance aluminum-based MMCs. The reinforcements in aluminum matrix composites could be in the form of particulates, whiskers, and continuous fiber or discontinuous fiber, where weight or volume fraction varies from a few percentages to $60 \%$. Properties of aluminum metal matrix composites can be customized as per the demand of the industry by getting the appropriate combination of the metal matrix, reinforcements, and selective processing route. Nowadays many grads of aluminum matrix composites are fabricated by different routes where in situ route processing is more attractive compared with conventional ex-situ process because it delivers excellent wettability, thermally stability of reinforcements, the bonding strength between reinforcements and matrix, cohesive atomic structure, and fine grain size of reinforcements (specifically nano size). The devoted research work of aluminum matrix composites during the last three-decade generates a wealth of knowledge on the effect of reinforcements vis-à-vis mechanical, chemical, tribological properties of aluminum matrix composites. The acceptance of the aluminum matrix composites as engineering materials depends not only on the performance advantages of the composites, but it also depends upon the cheap, easy, and familiar fabrication technologies for these tailored materials.
\end{abstract}

Keywords: Reinforcements; MMC (metal matrix composite); in-situ; composites.

*Corresponding author: Nishith Rathod, nishith.rathod@ckpcet.ac.in, nishith11679@gmail.com 


\section{Introduction}

All monolithic materials have their limitation to achieving the right combinations of mechanical, tribological, corrosion, magnetic, electric property, but to overcome and the ever-increasing demand of modern technology, composites are most auspicious materials in recent years [1]. Well established most common routes to fabricate composites are casting and powder metallurgy by adding reinforcements (dispersion strengthen mechanism are also very popular for the same) like oxides, carbides, nitrides, and borides [2-4]. A substantial number of research work and improvement of aluminum matrix composites is observed in these years. There are so many techniques have been industrialized and applied to the fabrication of aluminum matrix composites, such as mechanical stir casting, ultrasonic vibration-assisted stir casting, modified stir casting (two-stage), pressure and pressureless infiltration, powder metallurgy, selective laser melting (SLM), accumulative roll bonding (ARB), squeeze casting, hot pressing, spark plasma sintering (SPS), high pressure die casting, etc. Remarkable factors affecting the response of the aluminum matrix composites are the bonding strength of matrix and reinforcement interface, the chemistry, the size, shape, and distribution of reinforcement, and the matrix composition. Ductility of composites is reducing as the weight or volume fraction of the reinforcements increased, and simultaneously strength of composites is increased. Grain refinement is one of the popular ways to improve ductility and strength at ambient temperature. Under this situation, aluminum reinforced with ceramic particulates have significant potential in structural application due to their high specific strength, stiffness, and low density but negotiate the ductility of the composites [5-7]. Particulates are one of the promising reinforcements of materials used for aerospace, transportation, and industrial sectors for fabricating composites [8].

The aim of this paper is to show recent literature trend for the most significant reinforcements in aluminum-based composites: $\mathrm{SiC}, \mathrm{Al}_{2} \mathrm{O}_{3}, \mathrm{CNT}$ (carbon nanotube), $\mathrm{B}_{4} \mathrm{C}, \mathrm{Al}-\mathrm{Ti}, \mathrm{TiC}, \mathrm{TiB}_{2}$, Graphene ( $\mathrm{GO}$ and $\mathrm{RGO}$ ), and Carbon fiber $\left(\mathrm{C}_{\mathrm{f}}\right)$. Table 1 shows the summarized production techniques and outcomes related to the process for the most studied reinforcements in aluminum-based composites. 
Table 1. Critical outcome of different reinforced Al MMCs.

\begin{tabular}{|c|c|}
\hline Reinforcements & $\begin{array}{l}\text { Manufacturing } \\
\text { Process }\end{array}$ \\
\hline SiC [9-22] & 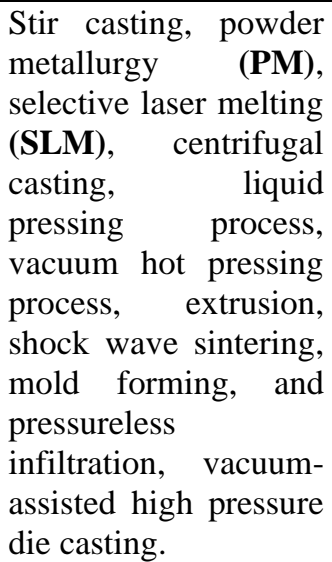 \\
\hline
\end{tabular}

$\mathrm{Al}_{2} \mathbf{O}_{3}[23-28]$

CNT [29-35]
Flake Powder Melt (FPM), Two-step stir casting, Squeeze casting, Selective laser melting (SLM), Gas pressure infiltration, Pressureless infiltration, Freeze casting.

PM (along with cryogenic- milling), Solution Ball milling, Sandwich technique, Ball milling.

\section{Significant Outcome}

- The optimum volume fraction is 50-60 vol\%.

- As reducing particle size micro to nano and to increase volume fraction, it improves mechanical, tribological property, and flexural strength. Simultaneously reduces corrosion rate and coefficient of thermal expansion.

- It improves wettability with fine particle size.

- Thermal conductivity improves with annealed samples.

- There is a significant decrease in wear rate at $450{ }^{\circ} \mathrm{C}$ in $\mathrm{Al} / \mathrm{SiC}$ nanocomposites systems.

- The optimum volume fraction is 0-30 vol\%.

- Flow stress increases with strain rate and decreases with temperature in the range of $480-$ $360 \quad{ }^{\circ} \mathrm{C} \quad$ in $\quad \mathrm{Al} / \mathrm{Al}_{2} \mathrm{O}_{3}$ nanocomposites systems.

- As an increasing heating rate (directly putting inside the preheated furnace at $900{ }^{\circ} \mathrm{C}$ ), uniform distribution of $\mathrm{Al}_{2} \mathrm{O}_{3}$ particles are observed.

- The optimum volume fraction is 0-2 vol\%.

- It significantly improves the mechanical property (tensile strength, yield strength, and 
$\mathbf{B}_{4} \mathbf{C}$ [36-39]

Al-Ti base particle [40-43]

TiC $[44,45]$

$\operatorname{TiB}_{2}[46-51]$
Stir casting, Powder injection, ultrasonic cavitation- assisted casting.

Stir casting, PM, Hot pressing and Hot extrusion, ultrasonic vibration-assisted casting, squeeze casting, Hot pressure sintering approach.

PM, Hot pressing combines with hot extrusion.

Stir casting, Mechanical stirring, In situ technique, Cryomilling - spark plasma sintering, and Pressure infiltration. elastic moduli) and decreases electrical conductivity.

- Optimum weight percentage is 5$20 \mathrm{wt} \%$.

- In $\mathrm{Al} / \mathrm{B}_{4} \mathrm{C} / \mathrm{MoS}_{2}$ systems, as $\mathrm{MoS}_{2}$ weight percentage increases, hardness and fracture toughness decreases considerably.

- As reducing particle size micro to nanocomposites tensile strength, impact strength, and ductility increased.

- It is observed that increasing the temperature coefficient of thermal expansion is also increases.

- Ti-Al-Nb-B (TNM) crystalline particles have a very good bonding with the matrix.

- It improves mechanical and tribological properties.

- The optimum volume fraction is 20-30 vol\%.

- It improves mechanical properties.

- Optimum weight percentage is 0 $20 \mathrm{wt} \%$.

- It improves compressive strength and coefficient of friction.

- It also improves the serviceability of composites at a higher temperature. 
$\begin{array}{llll}\text { Graphene (GO } & \text { Spark plasma } & \text { The optimum volume fraction is } \\ \text { and RGO) }[52-54] & \begin{array}{l}\text { sintering, High energy } \\ \text { ball milling, and }\end{array} & \begin{array}{l}0-1 \text { vol\%. } \\ \text { - Researchers have objected to the }\end{array}\end{array}$ $\begin{array}{ll}\text { Vacuum hot pressing. } & \text { Researchers have objected to the } \\ \text { study on uniform distribution of }\end{array}$ graphene and protect graphene structure while synthesizing.

- It improves mechanical properties by adding only 0.25 vol\% of graphene.

\begin{tabular}{|c|c|c|}
\hline $\begin{array}{l}\text { Carbon } \\
\left(\mathbf{C}_{\mathrm{f}}\right)[55-57]\end{array}$ & fiber & $\begin{array}{l}\text { Electromagnetic } \\
\text { casting method, self- } \\
\text { propagating high- } \\
\text { temperature synthesis, } \\
\text { semi-solid rolling } \\
\text { method. }\end{array}$ \\
\hline
\end{tabular}

- It improves wetting behavior by adding different stabilizer who creates $\mathrm{Ni} / \mathrm{P}, \mathrm{Ni}-\mathrm{Al}-\mathrm{Zr}, \mathrm{Zr}-\mathrm{C}$ interlayer, and it is specifically used to improve bending strength of composites in a structural application.

\section{Effect of reinforcements in aluminum-based systems}

\section{$\mathrm{SiC}$ reinforced aluminum-based metal matrix composites}

$\mathrm{SiC}$ is one of the lightest and hard ceramic particulates used as reinforcements in the aluminum-based metal matrix composites. Zakaria et al. [9] discussed the $\mathrm{Al} / \mathrm{SiC}$ composite material produced by the powder metallurgy process. They observed significant improvement in corrosion resistance of $\mathrm{Al} / \mathrm{SiC}$ composite by reducing the size of the $\mathrm{SiC}$ particle from micro to nano and increasing the volume fraction in the composite; authors noted that the $\mathrm{Al} / \mathrm{SiC}$ composite, compared to the pure aluminum, could be exposed at a higher corrosion rate on 50 and $75{ }^{\circ} \mathrm{C}$ in 3.5 wt. \% $\mathrm{NaCl}$ aqueous solution [9]. In the hybrid composites, two or more reinforcements are added in the metal matrix simultaneously; this improves the wettability of reinforcements and metal matrix. One of the hybrid composites is $\mathrm{Al}-\mathrm{Mg}-\mathrm{Si} / \mathrm{SiC}$ + rice-husk hybrid composite (with mixing ratio of rice husk and $\mathrm{SiC}$ was $0: 1,1: 3,1: 1,3: 1$, and 1:0), fabricated by double stir casting process [10]. Here, the authors observed that hybrid composite improved corrosion resistance compares to base alloy in $3.5 \% \mathrm{NaCl}$ aqueous solution. $\mathrm{Al}_{4} \mathrm{SiC}_{4}+\mathrm{SiC} / \mathrm{Al}$ in situ hybrid metal matrix composite could also be fabricated successfully by a selective laser melt (SLM) process [11]. It was observed that improvement in the wettability of reinforcement to the matrix could be reached by adding fine $\mathrm{SiC}$ particles (size of particles was $5 \mu \mathrm{m}$ ). The results were improved by $19 \%$ in the coefficient of friction, and a $66 \%$ reduced wear rate by adding fine $\mathrm{SiC}$ particles compare to coarse particles [11]. SiC/Al composites fabricated by the centrifugal casting process were examined in the literature [12]; $\mathrm{SiC} / \mathrm{Al}$ prepared slurry was poured at $700{ }^{\circ} \mathrm{C}$ in preheated graphite mold at $250{ }^{\circ} \mathrm{C}$ with $700 \mathrm{rpm}$. Composite slurry caused to lead and to refine primary $\alpha(\mathrm{Al})$ phases, instance segregation of phase and modified eutectic silicon. Due to centrifugal force, $\mathrm{SiC}$ 
particles and some primary $\alpha(\mathrm{Al})$ phases drifted to the outer region of the castings, resulting in a particle-free zone in the middle zone of the casting sand a macro-segregation along the centrifugal force direction [12]. Hyungsoo Lee et al. examined A356/SiC composite fabricated via liquid press method [13]. Under this process, $56 \mathrm{vol} \% \mathrm{of} \mathrm{SiC}$ was achieved and found the homogeneous distribution of particles; which shows the best combination of strength, strain, and highest dynamic toughness. Because the crack propagation was effectively blocked by the molten aluminum matrix and deformation band formation, while the T6-heat -treated A356/SiC composites not able to show high strength, but it resulted in lowest compressive strain [13]. Densely packed Al/SiC composites and $\mathrm{Al}$ used for finite element modeling and analysis of thermal expansion behavior was observed in the paper [14]. Effectiveness of the coefficient of thermal expansion (CTE) of composites was higher with a non-interpenetrating microstructure than that of the composites having interpenetrating microstructure [14]. Al/50 vol.\% SiC composites containing different sizes of $\mathrm{SiC}$ particles (average size of 23, 38, and $75 \mu \mathrm{m}$ ) prepared by the powder metallurgy method were reported in the literature [15]. Due to coarse $\mathrm{SiC}$ particles, high thermal conductivity and coefficient of thermal expansion were achieved, while fine particles were responsible for the decrease in coefficient of thermal expansion and increased the flexural strength of composites. It was found that annealed composites were slightly decreased flexural strength and coefficient of thermal expansion, and thermal conductivity was increased. Thermal conductivity depends on the particle size of reinforcements due to that as size reduces, the thermal conductivity was increased [15].

In recent years, one of the challenging tasks is to distribute CNT (carbon nanotube) in the metal matrix. A novel approach developed to disperse CNT in the matrix where $\mathrm{SiC}$ particles were used as "carrier" was presented in the study [16]. It was shown that with the help of the chemical vapor deposition method, CNT was grown on the micro size surface of $\mathrm{SiC}$, forming nano and or micro-sized hybrid composites named $\mathrm{Al} / \mathrm{SiC}$ (CNT). Three different sizes of $\mathrm{SiC}$ particles $(13,7$, and $2.5 \mu \mathrm{m})$ were selected for fabrication, and remarkable strength was achieved for $\mathrm{SiC}$ particle size of $7 \mu \mathrm{m}$ [16]. Al6082-5\% SiC$5 \%$ Graphite (Gr) hybrid composite was fabricated by stir casting method $\left(500{ }^{\circ} \mathrm{C}\right.$ preheated $\mathrm{SiC}$ particles were added in the metal matrix and mechanically stirred at 400 rpm for 10 minutes.) [17]. The wear coefficient of hybrid composites was slightly decreased after annealing, and it increases with an increase in load and grit size of $\mathrm{SiC}$ and $\mathrm{Gr}$ [17]. Al2024-10 vol.\% SiC composites can be produced via powder thixoforming [18]. First Al particles and oxides $10 \mathrm{wt} . \% \mathrm{SiC}$ particles were ball milled, followed by thixoforming at $400{ }^{\circ} \mathrm{C}$ with punch velocity $60 \mathrm{~mm} / \mathrm{s}$ and pressure of $160 \mathrm{MPa}$ [18]. The tensile property of the composites was depending upon mold temperature because it influences the recrystallization behavior, plastic deformation during the thixoforming process, secondary solidification structure behavior, and compactness of secondary solidified structure. Improvement in tensile strength was achieved at $350{ }^{\circ} \mathrm{C}$ of mold, which was observed as an improvement of $235.4 \%$ in tensile strength and reduction in ductility of about $31 \%$ [18]. $\mathrm{SiC}_{\mathrm{nw}} / 6061 \mathrm{Al}$ composites fabricated by extrusion was reported [19], where hot extrusion was carried out at $520^{\circ} \mathrm{C}$ with $10 \mathrm{~mm} / \mathrm{s} \mathrm{ram}$ speed with extrusion ratio was 11:1. Composites showed a significant increase in mechanical property, where the increase in elastic moduli was reported predominantly due to the densification effect. After the extrusion process, the ratio of strengthening efficiency was improved by 0.6 [19]. Al/SiCn-carbon hybrid composite fabricated by mechanical 
alloying of composites powder followed by hot pressing was presented in the literature [20]. There were two types of carbon (glass carbon and multiwall carbon nanotube) used for fabrication. In the presence of the carbon, the coefficient of friction stabilizes, only glass carbon composites show better results for wear resistance than the multiwall carbon nanotube. The most considerable alteration in wear test was observed at $450{ }^{\circ} \mathrm{C}$ with the Al-SiCn-glass carbon composites [20]. Al6061/SiC and A356/SiC composites were fabricated by the vacuum-assisted high-pressure die casting method [21]. The major outcomes of the paper [21] were to achieve a homogenous distribution of SiC particles, to study $3 \mathrm{D}$ characteristics of pores, improvement in particles to matrix interface, and to examine mechanical properties of the composites. Compared to the gravity die casting process, a vacuum-assisted high pressure die casting method shows significant improvement [21]. Functionally continuous graded AA7075/SiC composites with $6.5 \%$ $\mathrm{SiC}$ and $9.5 \% \mathrm{SiC}$ particles fabricated by the centrifugal casting process [22]. As particle volume fraction increase, the density of the composites decreased due to increment in casting defects. An increase in sliding speed, load, and sliding distance leads to an increase in the wear rate of functionally graded composites, and results showed functionally graded $\mathrm{A} 1 / 9.5 \% \mathrm{SiC}$ composites were superior to the cast and other composites [22].

\section{$\mathrm{Al}_{2} \mathrm{O}_{3}$ reinforced aluminum-based metal matrix composites}

The $\mathrm{Al}_{2} \mathrm{O}_{3}$ is one of the most attractive additives in aluminum matrix composites for improving mechanical properties. In the paper [23], flake powder metallurgy (FPM) was used to fabricate $\mathrm{Al} / \mathrm{Al}_{2} \mathrm{O}_{3}$ nanocomposites via an in situ routes. FPM method produces intergranular $\mathrm{Al}_{2} \mathrm{O}_{3}$ nanoparticles with a lamellar shape in the aluminum matrix by refining the thickness of the ball-milled aluminum flakes [23]. The compression test was used to study the effect of flow stress by increasing the strain rate; the authors show that $\mathrm{Al}_{2} \mathrm{O}_{3}$ particles reinforce the aluminum matrix. It was observed [23], form the microstructure evaluation and processing map, that dynamic recrystallization occurred at the $480{ }^{\circ} \mathrm{C}$ with a strain rate from 0.001 to $0.01 \mathrm{~s}^{-1}$. The optimum hot working condition was at $480{ }^{\circ} \mathrm{C} / 0.001 \mathrm{~s}^{-1}$ [23]. In another paper [24], two-step stir casting method was used to fabricate hybrid aluminum composites with alumina, rice husk ash (RHA), and graphite (as cast AA6063 alloy was first melted at $720 \pm 30^{\circ} \mathrm{C}$, after that it was cooled at its semisolid condition at $600{ }^{\circ} \mathrm{C}$; preheated alumina, RHA, and graphite was added with mechanical stir at $400 \mathrm{rpm}$ for 10 minutes) [24]. The composites with graphite show low susceptibility of wear compared to composites with alumina and RHA. As graphite content increases from 0.5 to $1.5 \mathrm{wt}$ \% wear resistance decreases [25]. Stir method was used to fabricate hybrid aluminum matrix composites with $\mathrm{SiO}_{2}$ and $\mathrm{Al}_{2} \mathrm{O}_{3}$ reinforcement [26]. As the weight percentage of $\mathrm{SiO}_{2}$ particles increases, the dendrite arm spacing of $\alpha$ $\mathrm{Al}$ grain decreases. As $\mathrm{SiO}_{2}$ increased liquids temperature decreased [26]. The elastoplastic finite element model was studied for the thermomechanical behavior of aluminum composites reinforced with alumina particles [27]. The FE results have a reasonable correlation with the experimental data, and the effects of microstructural parameters, voids, and properties of the constituents were further discussed. In order to study the influence of voids on the elastoplastic behavior of composites, the GursonTvergaard-Needleman (GTN) model is applied [27]. Indigenously developed stir casting technique was used to fabricate aluminum matrix composites reinforced with zircon tailing sand (comprised of $\mathrm{SiO}_{2}$ and $\mathrm{Al}_{2} \mathrm{SiO}_{5}$ ). Particle dispersion and wettability at 
$\mathrm{SiO}_{2} / \mathrm{Al}$ interface were improved with the optimized process parameters (i.e., particles preheating at $700{ }^{\circ} \mathrm{C} \times 1 \mathrm{~h}$, feeding rate at $10 \mathrm{~g} / \mathrm{min}$ and stirring time for $10 \mathrm{~min}$ ) [28].

\section{CNT (carbon nanotube) reinforced aluminum-based metal matrix composites}

A carbon nanotube is a potential reinforcement for improving mechanical and tribological properties where its volume fraction is very nominal compared to other reinforcements (0.1-1 vol.\%). Biao Chen et al. [29] studied microstructure, mechanical, and conductive properties for $\mathrm{Al} / \mathrm{CNT}$ composites, fabricated by powder metallurgy. They show a uniform distribution of CNTs in the aluminum matrix within a low content (0.75 vol\% CNTs), but as volume fraction increases, agglomeration of CNT occur, reducing tensile properties. Thermal conductivity and electrical conductivity decreased, and yield strength was increased due to grain refine and oxygen-rich interface [29]. The new approach, using solution ball milling, was developed for the fabrication of aluminum matrix composites reinforced with CNT [30]. Under this approach, uniform dispersion of CNT was observed with a large aspect ratio, small damage of CNT and without the unbundling of CNT in aluminum powders [30]. Carbon nanotube reinforced aluminum matrix composites were synthesized using an equal-channel angular extrusion route [31]. The well-densified composites with only 2 vol. $\%$ of CNTs exhibit an approximately $30 \%$ increase in yield strength compared to the pure aluminum [31, 32]. The load transfer capability of the interface was studied for multi-walled carbon nanotube reinforced in aluminum matrix composites. It was observed that the load transfer capacity and yield strength improved with the presence of the $\mathrm{Al}_{4} \mathrm{C}_{3}$ as interface developed between reinforced and aluminum matrix with appropriate quantity under precisely controlled heat treatment [33]. A small addition of CNTs via the powder metallurgy route leads to a significant enhancement in stiffness, strength, and elasticity of aluminum matrix composites. Under this strength, enhancement was proportional to CNT diameter and the fracture behavior of $\mathrm{Al} / \mathrm{CNT}$ composites. It was mainly governed by the size characteristics of CNTs [34]. Al2009 aluminum alloy matrix composites were reinforced with highly dispersive carbon nanotubes (CNTs) prepared via cryogenic milling combined with powder metallurgy [35]. Most CNTs retained tubular structure in composites except only minimal ones reacted with aluminum and formed the $\mathrm{Al}_{4} \mathrm{C}_{3}$ interface. With the increasing addition of CNTs in composites, dispersity gradually decreased, and limited dispersion was found when CNTs content is $1.5 \mathrm{wt} . \%$ [35].

\section{$B_{4} C$ reinforced aluminum-based metal matrix composites}

$\mathrm{B}_{4} \mathrm{C}$ is used to enhance the mechanical and tribological properties of the aluminumbased systems. $\mathrm{Yu}$ Li et al. studied the mechanical and microstructural effects of $\mathrm{B}_{4} \mathrm{C}$ and $\mathrm{B}_{4} \mathrm{C}-\mathrm{Al}_{3} \mathrm{Ti}$ reinforced aluminum composites fabricated via a stir casting technique [36]. They found that a higher amount of $\mathrm{Ti}$ in the matrix leads to increase volume fraction and particle size of $\mathrm{Al}_{3} \mathrm{Ti}$, with a dense interface between matrix and reinforcements, improving mechanical properties of the composite compared to base metal [36]. Research of $10 \mathrm{wt} . \% \mathrm{~B}_{4} \mathrm{C}-\mathrm{MoS}_{2}$ hybrid aluminum alloy composite, reinforced using the stir casting route, show that increasing share of $\mathrm{MoS}_{2}$ reduces the hardness and toughness of hybrid composites but simultaneously, reduces the wear rate and friction coefficient of the hybrid composites [37]. The technique for stir casting with ultrasonic cavitation contains the following steps: first melted aluminum is stirred mechanically ( $400 \mathrm{rpm}$, for 10 minutes) and $\mathrm{B}_{4} \mathrm{C}$ particles were added, after that ultrasonic probe was introduced, generating 20 $\mathrm{kHz}$ frequency ultrasonic vibration, for preparing micro and nanocomposites by varying 
weight percentage of $\mathrm{B}_{4} \mathrm{C}$ particles (2, 4, 6, 8, and $10 \mathrm{wt} . \%$ ) [38]. By increasing the share of $\mathrm{B}_{4} \mathrm{C}$ particles, up to $8 \%$, the wear rate decreased significantly in the nanocomposites compare to micro composites [38]. In another study [39], the modified stir casting method was used to prepare aluminum alloy composites reinforced with $\mathrm{B}_{4} \mathrm{C}$, from 5 to $20 \mathrm{wt}$. $\%$. Microstructure observation showed that increasing the share of $\mathrm{B}_{4} \mathrm{C}$ particles affects their distribution along the dendrite arm, with clustering and agglomeration of reinforcements [39].

\section{Al-Ti based particles reinforced aluminum-based metal matrix composites}

Al-Ti based particles are used to enhance the mechanical and tribological properties of the aluminum-based systems. High-intensity ultrasonic vibration technique was used to fabricate aluminum alloy-based metal matrix composites reinforced with $\mathrm{Al}_{3} \mathrm{Ti}$ [40]; it was observed by microstructure evaluation that fine $\mathrm{Al}_{3} \mathrm{Ti}$ particles were evenly distributed in the $\alpha$-Al matrix. Mechanical properties of composites were improved significantly due to evenly distributed $\mathrm{Al}_{3}$ Ti particles [40]. Powder metallurgy through hot pressing and hot extrusion was carried out to fabricate the lightweight composites reinforced with Ti-Al-Nb-B (TNM) [41]. Here, hot pressing was carried out at $400{ }^{\circ} \mathrm{C}$ with $600 \mathrm{MPa}$ for $10 \mathrm{~min}$, followed by hot extrusion at $700 \mathrm{MPa}$ with $400{ }^{\circ} \mathrm{C}$ for 30 to 60 min depending upon TNM weight percentage. Precipitation of Si particles in the aluminum alloy matrix due to TNM reinforcements provided excellent bonding strength [41]. TNM reinforced aluminum alloy Al-12Si showed improvement in YS, UTS, and specific strength compare to base alloy [41]. Squeeze casting process (molten aluminum alloy at $760^{\circ} \mathrm{C}$ was pouring in the steel mold followed by $15 \mathrm{MPa}$ pressure for 30 minutes) was used to fabricate aluminum-based metal matrix composites reinforced with woven $\mathrm{Ti}_{6} \mathrm{Al}_{4} \mathrm{~V}$ fabric for short solidification time [42]. TEM analysis shows that $\mathrm{TiAl}_{3}$ as an interfacial reaction product and Ti-Al diffusion layer were formed ob interface during fabrication. Woven $\mathrm{Ti}_{6} \mathrm{Al}_{4} \mathrm{~V}$ reinforced composites improved the hypervelocity impact strength of aluminum alloy [42]. Hotpress sintering methodology is a sintering process carried out at $620^{\circ} \mathrm{C}, 40 \mathrm{MPa}$ pressure with $1 \mathrm{hr}$ holding time, and is used for fabricating aluminum composites reinforced with $\mathrm{Ti}_{3} \mathrm{AlC}_{2}$ and $\mathrm{Cu}$ coated $\mathrm{Ti}_{3} \mathrm{AlC}_{2}$ [43]. It was observed that $\mathrm{Ti}_{3} \mathrm{AlC}_{2}$ show poor wettability with aluminum [43].

\section{TiC reinforced aluminum-based metal matrix composites}

TiC particle reinforcement is used to enhance the mechanical and tribological properties of the aluminum-based systems. Nanocrystalline TiC powder with $35 \mathrm{~nm}$ in size was fabricated via the mechanical alloying method [44]. The hardness of material was relatively improved by preserving the nanocrystalline structure of $\mathrm{TiC}$ [44].

$\mathrm{Al}-\mathrm{Cu}-\mathrm{Mg}$ matrix composites reinforced with 5-9 vol.\% nano-sized $\mathrm{TiC}_{\mathrm{x}}$ particles fabricated by combustion synthesis (CS), and hot-pressing process combined with hot extrusion was presented in the literature [45]. Ball milled powder of aluminum alloy and reinforcements were set in the self-made furnace for compaction and combustion synthesis. Combustion synthesis happens when the temperature measured by the W5Re26 thermocouple suddenly rose rapidly. The tensile strength, yield strength, and fracture strain of the composites (5 vol. $\%$ nano-sized $\mathrm{TiC}_{\mathrm{x}} / \mathrm{Al}-\mathrm{Cu}-\mathrm{Mg}$ ) were simultaneously improved compared with base alloy fabricated via powder metallurgy at $300{ }^{\circ} \mathrm{C}$ [45]. 


\section{$\mathrm{TiB}_{2}$ reinforced aluminum-based metal matrix composites}

$\mathrm{TiB}_{2}$ particle reinforcement improves mechanical behavior, such as stiffness, strength, and wear resistance. Outstanding reinforcements occur because of its good thermodynamic stability, excellent resistance to mechanical erosion, high corrosion resistance, high melting point $\left(2790^{\circ} \mathrm{C}\right)$, high hardness $(960 \mathrm{HV})$, and low density [4650].

The salt-metal synthesis route was successfully used to prepare $\mathrm{Al}-4.5 \mathrm{Cu} / 5 \mathrm{vol} . \%$ $\mathrm{TiB}_{2}$ composites: a modified mechanical stirring, where two kinds of pure salts $\mathrm{KBF}_{4}$ and $\mathrm{K}_{2} \mathrm{TiF}_{6}$ were used for synthesis in the aluminum alloy melt at $830{ }^{\circ} \mathrm{C}$ for 30 minutes [46]. $\mathrm{TiB}_{2}$ particles were uniformly distributed along the grain boundary in the matrix, and lots of dispersed particles with a size under $0.4 \mu \mathrm{m}$ were also found. YS and UTS of the composites were enhanced by $85 \%$ and $46 \%$, respectively [46, 47]. Salt-metal synthesis route was used to study [48] surface integrity (surface roughness, residual stress, microhardness, surface topology, and defects). The result shows that the feed rate was the dominant impact on surface roughness [48]. Besides, unlike aluminum matrix composites, pull out, or fractured particles were rarely found on the machined surface of in situ $\mathrm{Al}_{2} / \mathrm{TiB}_{2}$ composites [48]. Nanostructured Al5083 aluminum alloy-based composites with nano- $\mathrm{TiB}_{2}$ reinforcement particles were fabricated via cryogenic grinding and spark plasma sintering (SPS) [49]. The interface between the aluminum matrix and $n-\mathrm{TiB}_{2}$ appears to be free of defects and without apparent discontinuities. The strength was $20 \%$ higher than that of an equivalent SPs consolidated Al5083 without reinforcement [49]. Haitao Chi et al. [50] studied characteristics of friction and wear transition from the running-in stage to the steady-state stage for an aluminum-based composite containing $\mathrm{TiB}_{2}$ particles and produced by a pressure infiltration technique (60 $\mathrm{MPa}, 770{ }^{\circ} \mathrm{C}$ molten aluminum alloy was infiltrated in the $\mathrm{TiB}_{2}$ for $30 \mathrm{~min}$ ). An increase of friction coefficient was caused by the abrasion of pulled out $\mathrm{TiB}_{2}$ particles. Also, at a steady-state friction coefficient of 0.6 , severe three-body abrasive wear and oxidative wear were the dominant wear mechanism [50]. The salt-metal synthesis route was used to fabricate $\mathrm{Al} / \mathrm{TiB} 2$ in situ composites [51]. With EMS microstructure characterization, 80 to $90 \%$ of the $\mathrm{TiB}_{2}$ particles were found to be in the range of $100-150 \mathrm{~nm}$. The distribution of $\mathrm{TiB}_{2}$ particles was almost homogenously near the solidified casting. Due to favorable microstructure features, consequent improvements in mechanical properties like hardness, tensile, and wear properties were achieved [51].

\section{Graphene reinforced aluminum metal matrix composites}

Recently researchers are highly attracted by graphene because a small addition of graphene $(0.1$ vol.\%) leads to a significant change in mechanical and tribological properties of aluminum-based systems [52-54]. It is very much significant to find the consistent distribution of graphene in the matrix and to preserve the structure of graphene. Xin Gao et al. [52], fabricate aluminum matrix composites reinforced with GO (graphene oxide) sheets, using the powder metallurgy route. GO sheets were homogeneously absorbed on the surface of CTAB (coated by Cetyl trimethyl ammonium bromide) coated aluminum powder. UTS increased to some point, and after the addition of higher content of graphene begins to decline.

Spark plasma sintering method was used for consolidating the aluminum powder with graphene, hexagonal boron nitride $(\mathrm{hBN})$, and molybdenum disulfide particles at $500{ }^{\circ} \mathrm{C}$, with heating rate $225^{\circ} \mathrm{C} / \mathrm{min}$, and dwelling time of $2 \mathrm{~min}$ with argon atmosphere 
[53]. The friction coefficient decreased considerably, with an increase in 2D crystal particles [53]. High energy ball milling with vacuum hot pressing processes were used to fabricate aluminum matrix composites reinforced with graphene nanosheets (GNSs) [54], achieving good wettability and bonding strength of GNSs and aluminum; the $\mathrm{Al}_{4} \mathrm{C}_{3}$ phase with granular and rod-like morphology was found in the matrix. As graphene nanosheets increase in composites, the content of the $\mathrm{Al}_{3} \mathrm{C}_{4}$ phase was increased [54]. The YS, UTS of composites (Al-0.25GNSs) were increased compared to base aluminum [54].

\section{Carbon fiber ( $C f)$ reinforced aluminum-based metal matrix composites}

Carbon fiber (Cf) is mostly used for improving the flexural strength of aluminumbased systems. Woven carbon fibers reinforced, $\mathrm{Al}-5 \mathrm{Mg}$ matrix composites were successfully fabricated by an electromagnetic casting process [55]. The casting results indicated that the contact time between the molten metal and the carbon fibers was vital to the bonding degree: increasing the solidification time reduces the cavity defects, located near the interface; however, an overly long solidification time would result in a tendency to crack in the centers of the woven fibers. Three-point bending tests showed that the bending strength of the composite had an improvement for $33.6 \%$ than that of the Al-alloy [55]. The development of a high-efficiency joining method of $\mathrm{C}_{\mathrm{f}} / \mathrm{Al}$ composites and TiAl alloys under the heat effect of laser-ignited self-propagating high-temperature synthesis (SHS) was reported in the literature [56]. The sound joint was obtained; with the joining pressure of $2 \mathrm{MPa}$ and with additive filler metals: joint shear strength reached a maximum of $41.01 \mathrm{MPa}$ [56]. $\mathrm{C}_{\mathrm{f}} / \mathrm{Al}$ composites were joined with $\mathrm{Ti}-\mathrm{Al}$ intermetallic by a novel laser-induced self-propagating high-temperature synthesis joining method (SHS) [57]. A nanoscale thin $\mathrm{Zr}-\mathrm{C}$ layer is formed on the $\mathrm{NiAl}_{3} / \mathrm{C}_{\mathrm{f}}$ interface, thus greatly improving the bonding quality on the $\mathrm{C}_{\mathrm{f}} / \mathrm{Al}$ side. Appropriate $\mathrm{Zr}$ content increases the joint density and enhances the wettability of the interlayer products on the carbon fibers. The joint shear strength under that condition reaches the maximum value of $68.71 \mathrm{MPa}$ [57].

Figure 1 shows the recent literature trend for the most significant reinforcements in aluminum-based composites; the greatest attention is paid to $\mathrm{SiC}, \mathrm{Al}_{2} \mathrm{O}_{3}$, and $\mathrm{CNT}$ reinforcements. 


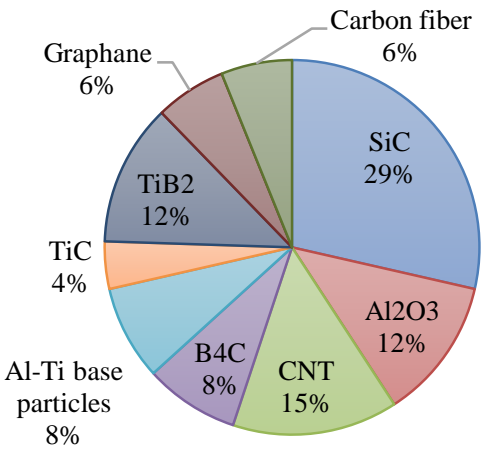

$\begin{array}{lll}\square \mathrm{SiC} & \square \mathrm{A} 12 \mathrm{O} 3 & \square \mathrm{CNT} \\ \square \mathrm{B} 4 \mathrm{C} & \square \mathrm{Al} \text {-Ti base particles } & \square \mathrm{TiC} \\ \square \mathrm{TiB} 2 & \square \text { Graphane } & \square \text { Carbon fiber }\end{array}$

Fig. 1. Contribution of the reinforcements in aluminum-based systems [9-57].

\section{Summary}

Devoted research and development of aluminum matrix composites are observed in the advanced application of automobile structural, aviation industries, marine industries, shipbuilding, a critical component of space craft's where monolithic materials or alloys have its limitation to give right strength, stiffness, toughness, and density. Numerous process have been industrialized and applied to the fabrication of aluminum matrix composites, such mechanical stir casting, ultrasonic vibration-assisted stir casting, modified stir casting (two-stage), pressure and pressureless infiltration, powder metallurgy, selective laser melting (SLM), accumulative roll bonding (ARB), squeeze casting, hot pressing, spark plasma sintering (SPS), high pressure die casting, etc. Remarkable factors affecting the response of the aluminum matrix composites are the bonding strength of matrix and reinforcement interface, the chemistry, the size, shape, and distribution of reinforcement, and the matrix composition. $\mathrm{SiC}, \mathrm{Al}_{2} \mathrm{O}_{3}, \mathrm{TiB}_{2}, \mathrm{~B}_{4} \mathrm{C}$, TiC, CNT, Carbon fiber, Graphite, Graphene, Al-Ti based particle, are some of the common reinforcements utilize to fabricate aluminum-based metal matrix composites (MMCs).

From Figure 1, it is observed that $\mathrm{SiC}$ [9-22] is frequently utilized as reinforcement. For improving mechanical and tribological properties, most common reinforcements are $\mathrm{SiC}, \mathrm{CNT}, \mathrm{B}_{4} \mathrm{C}$, Al-Ti based particles, TiC, graphene, and $\mathrm{C}_{\mathrm{f}}$. TiB2 is using for improving the compressing strength and serviceability of material at higher temperatures. Ductility of composites is reducing as the weight or volume fraction of the reinforcements increased, and simultaneously strength of composites is increased. Grain refinement is one of the popular ways to improve ductility and strength at ambient temperature: with smaller grain size, mechanical, tribological, and chemical properties were improved significantly; on the other hand, wettability and interfacial strength of matrix and reinforcements are also improved. The acceptance of the aluminum matrix 
composites as engineering materials depends not only on the performance advantages of the composites, but it also depends upon the cheap, easy, and familiar fabrication technologies for these tailored materials.

\section{References}

[1] John V. Foltz, Charles M. Blackmon, ASM Handbook, Volume 2: Properties and Selection: Nonferrous Alloys and Special-Purpose Materials, ASM Handbook Committee, 903-912.

[2] V.K. Lindroos, M.J. Talvitie: J Mater Process Technol, 53 (1995) 273.

[3] W.C. Jr. Harrigan: Mater Sci Eng: A, 244 (1998) 75.

[4] J.W. Kaczmar, K. Pietrzak, W. Wlosinski: J Mater Process Technol, 106 (2000) 58.

[5] D. B. Miracle: Compos Sci Technol, 65 (2005) 2526-2540.

[6] Y. Sahin, M. Acilar: Composites, Part A, 34 (2003) 709-718.

[7] A. M. Hassan, A.T. Mayyas, A. Alrashdan, M. T. Hayajneh: J Mater Sci, 43 (2008) 5368-5375.

[8] Daniel B. Miracle and Steven L. Donaldson, Volume Chairs, ASM Handbook. Composites, vol. 21 (2001).

[9] H.M. Zakaria, and Ain Shams: Eng J, 5 (2014) 831-838.

[10] K. K. Alaneme, T. M. Adewale, P. A. Olubambi. J Mater Res Technol, 3 (2014) 9 16.

[11] Fei Chang, Dongdong Gu, Donghua Dai, Pengpeng Yuan: Surf Coat Tech, 272 (2015) 15-24.

[12] K. Wang, Z.M. Zhang, T. Yu, N.J. He, Z.Z. Zhu: J Mater Proc Tech, 242 (2017) 6067.

[13] Hyungsoo Lee, Seok Su Sohn, Changwoo Jeon, Ilguk Jo, Sang-Kwan Lee, Sunghak Lee: Mater Sci Eng A, 680 (2017) 368-377.

[14] N. K. Sharma, R. K. Misra, S. Sharma: Int J Solids Struct, 102-103 (2016) 77-88.

[15] Fei TENG, Kun YU, Jie LUO, Hong-jie FANG, Chun-li SHI, Yi-long DAI, Hanqing XIONG: Trans Nonferrous Met Soc China, 26(2016) 2647-2652.

[16] Shisheng Li, Yishi Su, Xinhai Zhu, HuilingJin, Qiubao Ouyang, Di Zhang: Mater Des, 107 (2016) 130-138.

[17] N.Ch. Kaushik, R.N. Rao: Trib Int, 103(2016) 298-308.

[18] P.B. Li, T.J. Chen, H. Qin: Mater Des, 112 (2016) 34-45.

[19] Ling Xin, Wenshu Yang, Qiqi Zhao, Ronghua Dong, Xue Liang, ZiyangXiu, Murid Hussain, Gaohui Wu: Mater Sci Eng A, 682 (2017) 38-44.

[20] Sopicka-Lizer, Jakub Wieczorek: Compos B, 108 (2017) 291-300.

[21] Q. Hu, H. Zhao, F. Li: Mater Sci Eng A, 680 (2017) 270-277.

[22] T. R. Prabhu: Archives of Civil and Mechanical Engineering, 17 (2017) 20-31.

[23] Y. Yang, Z. Zhang, X. Zhang: Mater Sci Eng A, 558 (2012) 112-118.

[24] N. Guo, B. Luan, F. He, Z. Li, Q. Liu: Scr Mater, 78-79 (2014) 1-4.

[25] K. K. Alaneme, K. O. Sanusi: Engineering Science and Technology, an International Journal, 18 (2015) 416-422.

[26] K. Wang, W. Li, J. Du, L. Yang, P. Tang: Thermochim Acta, 641 (2016) 29-38.

[27] N. K. Sharma, R. K. Mishra, S. Sharma: Comput Mater Sci, 115 (2016) 192-201.

[28] K. Wang, W. Li, J. Du, P. Tang, J. Chen: Mater Des, 99 (2016) 303-313.

[29] B. Chen, S. Li, H. Imai, L. Jia, J. Umeda, M. Takahashi, K. Kondoh: J Alloys Compd, 651 (2015) 608-615.

[30] B. Chen, S. Li, H. Imai, L. Jia, J. Umeda, M. Takahashi, K. Kondoh: Mater Des, 72 (2015) 1-8. 
[31] H. Zare, M. Jahedi, M. R. Toroghinejad, M. Meratian, M. Knezevic: Mater Des, 106 (2016) 112-119.

[32] H. Zare, M. Jahedi, M. R. Toroghinejad, M. Meratian, M. Knezevic: Mater Sci Eng A, 670 (2016) 205-216.

[33] W. Zhou, T. Yamaguchi, K. Kikuchi, N. Nomura, A. Kawasaki: Acta Mater, 125 (2017) 369-376.

[34] J. Xiang, L. Xie, S. A. Meguid, S. Pang, J. Yi, Y. Zhang, R. Liang: Comp Mater Sci, 128 (2017) 359-372.

[35] T. He, X. He, P. Tang, D. Chu, X. Wang, P. Li: Mater Des, 114 (2017) 373-382.

[36] Yu Li, Qiulin Li, Wei Liu, Guogang Shu: J Alloys Compd, 684 (2016) 496-503.

[37] V. V. Monikandan, M.A. Joseph, P.K. Rajendrakumar: Resource - Effic Techol, 2 (2016) S12-S24.

[38] R. Harichandran, N. Selvakumar: Arch Civ Mech Eng, 16 (2016) 147-158.

[39] R. Raj, D. G. Thakur: Arch Civ Mech Eng, 16 (2016) 949-960.

[40] G. Chen, X. Song, N. Hu, H. Wang, Y. Tian: J Alloys Compd, 694 (2017) 539-548.

[41] Z. Wang, K.G. Prashanth, A.K. Chaubey, L. Löber, F.P. Schimansky, F. Pyczak, W.W. Zhang, S. Scudino, J. Eckert: J Alloys Compd, 630 (2015) 256-259.

[42] Z. Zheng, D. Zhu, X. Ding, X. Li, W. Chen: Mater Des, 108 (2016) 86-92.

[43] S. Wang, S. Zhu, J. Cheng, Z. Qiao, J. Yang, W. Liu: J Alloys Compd, 690 (2017) 612-620.

[44] M. Krasnowski, S. Gierlotka, T. Kulik: Adv Powder Technol, 26 (2015) 1269-1272.

[45] L. Wang, F. Qiu, Q. Zhao, H. Wang, Q. Jiang: Mater Charact, 125 (2017) 7-12.

[46] Q. Gao, S. Wu, S. LÜ, X. Duan, P. An: Mater Des, 94 (2016) 79-86.

[47] Q. Gao, S. Wu, S. LÜ, X. Duan, P. An: J Alloys Compd, 692 (2017) 1-9.

[48] Y. Xiong, W. Wang, R. Jiang, K. Lin, G. Song: Int J Refract Met Hard Mater, 54 (2016) 407-416.

[49] M. Li, K. Ma, L. Jiang, H. Yang, E. J. Laverni, L. Zhang, J. M. Schoenung: Mater Sci Eng, A, 656 (2016) 241-248.

[50] H. Chi, L. Jiang, G. Chen, J. Qiao, X. Lin, G. Wu: Wear, 368 (2016) 304-313.

[51] S. Agrawal, A. K. Ghose, I. Chakrabarty: Mater Des, 113 (2017) 195-206.

[52] X. Gao, H. Yu, E. Guo, H. Zhang, X. Lin, L. Yao, B. Wang: Mater Des, 94 (2016) 54-60.

[53] J. Wozniak, M. Kostecki, T. Cygan, M. Buczek, A. Olszyna: Compo B, 111 (2017) $1-9$.

[54] G. Li, B. Xiong: J Alloys Compd, 697 (2017) 31-36.

[55] J. Zhang, S. Liu, Y. Lu, Y. Dong, T. Li: J Mater Process Technol, 231 (2016) 366 373.

[56] Z. Li, G. Feng, S. Wang, S. Feng: J Mater Process Technol, 32 (2016) 1111-1116.

[57] G. Feng, Z. Li, Z. Zhou, Y. Wang: Mater Des, 110 (2016) 130-137.

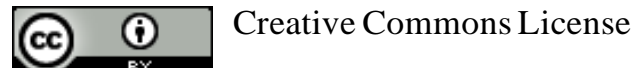

This work is licensed under a Creative Commons Attribution 4.0 International License. 